\title{
A Framework to Incorporate Quality Aspects for e-Learning System in a Consortium Environment
}

\author{
Wasefer Zaman, Partha Ghosh, Kalyankumar Datta, and Pramatha Nath Basu
}

\begin{abstract}
Around the world, many researchers and benchmarking institutions are working on the quality aspects of e-learning system. In a university consortium environment, there should be some sort of checkpoints for assessment of e-learning system because more than one member institution contributes to this e-learning environment.

There is a need to assure university consortium members that learners are using an e-learning system which is highly rated. All consortium members contribute to the management, administration and learning content. For example, before accepting from a provider, the content is thoroughly checked by a panel of experts who specialize in content, instructional designing of sequencing and profiles.

Similarly, for other areas, segregated forms of checkpoints and modules have been incorporated into the University Consortium Information System to incorporate the quality aspects. In this way, quality of e-learning system is improved. The present work discusses this process and, through investigations, suggests a framework to improve the quality aspects of the University Consortium Education System.
\end{abstract}

Index Terms-University consortium; web services; learning object (LO); pedagogical principles; SCO; SCORM; quality; e-learning.

\section{INTRODUCTION}

Online course offerings are increasing in number everyday and the number of learners who accept online courses is on the rise. Learners access educational information and content any where any time. So there is a need to evaluate the quality and effectiveness of the online courses and e-learning system.

University Consortium (a number of Universities from diverse geographical locations) would offer courses by providing a common portal. According to this approach all consortium members contribute to the management, administration and learning content [1].

Web Services technology remains a possible avenue in academic business that is incorporated in the management of resources to support e-learning activities such as running courses, support students, as well as conduct background processes seamlessly between member institutions and the University Consortium. This Web Services methodology also helps maintaining the interoperability among member institutions and University Consortium. The basis for web services incorporates standards for describing, publishing,

Manuscript received March 9, 2012; revised April 19, 2012.

Wasefer Zaman, Kalyankumar Datta, and Pramatha Nath Basu are with the School of Education Technology, Jadavpur University, Kolkata, 700032, India.

Partha Ghosh is with the Department of Mathematics, Haldia Government College, Medinipur, 721657, India. discovering and binding application interfaces.

E-learning systems' success depends on qualities governed by content, system and service. Content quality refers to the quality of e-learning content; system quality refers to the technology aspect of the system (ease of use, reliability, responsiveness etc.), service quality refers to instructor and technical support involvement in e-learning experience. The perceived task value refers to the importance attached by the learner to being successful in the course.

Characteristics of e-learning system, i.e., compatibility with different operating systems, performance, monitor resolutions, hardware and software for system accessibility should be checked properly before sending the system into a production environment.

In a University Consortium environment, all the members contribute to the management, administration and learning content for courses offered by the consortium. In this scenario, quality aspects of the e-learning contents and other quality aspects of the e-learning system should be taken into consideration. Although, framework for the improvement of the quality of the e-learning contents can be developed separately, in this work a new framework for the improvement of quality of e-learning system is proposed to make the University Consortium Information System [2] an integrated one.

\section{LITERATURE SURVEY}

Quality assessment in e-learning is a dynamically developing area. This aims at mitigating, or eliminating, the effects of lack of FTF (face-to- face) contact with the teacher and with the learning team. At the same time, it focuses sharply on the objective as well as the perceived quality of courses. As ICT (information and communication technology) and e-learning develop, more and more ingenious techniques are added to the e-learning process. Benchmarking and quality control should not only make the learning content, process and context comparable, but should also enable defining the highest quality solutions. It showcases the work of select international Institutions working on quality assessment and promotion and discusses some of the new approaches to benchmarking and quality assessment [3].

To evaluate the e-learning system quality, four quality characteristics, namely, Service Content, System Functionality, Information Technology and System Reliability have been proposed. These are appended with 11 sub-characteristics with the respective attributes by following the structure of standard IOS/IEC 9126. Results show that the proposed technique could be useful and effective for 
developing high quality systems [4].

Evaluation of the e-learning system quality can be done using neutral perspective, or by using the perspective of the beneficiary of formation or the perspective of formators. Neutral perspective can be used to evaluate the entire e-learning system. The perspective of the beneficiary of formation or the perspective of formators can be used to evaluate the main components of the e-learning system often used by the beneficiary of formations and by the formators. For measuring the e-learning system quality, focus must be on evaluating the following main components: e-learning infrastructure, e-learning formators, e-learning materials and e-learning activities [5].

LMSs quality evaluation method is represented by experts' additive utility function. This function is, in turn, based on the transformation of multiple criteria task into the one-criterion task by adding all criteria values together with their weights. Both LMSs general technological 'internal quality' and adaptation 'quality in use' evaluation criteria are analysed and incorporated into the comprehensive quality evaluation method. The LMSs quality evaluation criteria are further investigated as the possible LMSs optimisation parameters. The experts' additive utility function is explored for possible application in order to optimise LMSs according to personalised learner's needs [6].

A framework called TICS (Technology, Interaction, Content, Services) is proposed based on the concept of quality of e-learning systems. This framework focuses on the most important aspects to be considered when designing or evaluating an e-learning system. Emphasis is given on user-system interaction as one of such important aspects. Guidelines which address the TICS aspects and an evaluation methodology, called eLSE (e-Learning Systematic Evaluation), have been derived [7].

Integration of evaluative approaches into the development of e-learning is considered in order to enhance and assure the quality of the e-learning implementation. The evaluation processes were embedded within the regular cycle of the implementation, and data was gathered both purposively and opportunistically. Evaluation research was used to guide the processes, and a framework was applied that helped organize the wide range of disparate data collected [8].

\section{CRiteria For Evaluating the Quality of Courses OF AN ONLINE LEARNING SYSTEM}

Many institutions and companies are creating or adopting quality statements, standards, and criteria regarding the online courses they provide. University Consortium also, shares learners' information and learning content with member institutions. The essential elements of e-learning system quality are given below.

Instructional elements: Content expert(s) should authenticate the accuracy and quality of the e-learning content. The source and the author of the content should also be properly mentioned to avoid copyright and associated compensation issues.

- Quality: Appropriateness and quality of the learning content can be achieved through an accurate learner-centered design. Content quality need to be checked by experts in the respective subjects.

- Authenticity: Content needs to be checked against the original and it should be error free, complete and relevant.

- Validity: The period of time in which the content, which is to be learnt, is not needed to be updated.

- Media: During designing an e-learning system, designer must accurately choose media which are really complementary and enrich the contents without overloading the users' perceptual and cognitive systems.

- Presentation: This aspect refers to the way the learning material is taught. Interaction aspect is a crucial one for any technology-based learning. This aspect involves presentation of the educational material.

- Copyright: For information from secondary sources, copyright issue is very important. Organizations should have written or verbal consent of the source of the content and recognize the source as per the Intellectual Property Rights law of the country in which the law applies. The content developer must secure a copyright of the developed content.

Instructional design elements: Learning quality of an online course / content includes the following factors.

- Concept identification: Emphasis should be given on the identification of key concepts of the content during instructional design.

- Pedagogical styles: Clear and explicit teaching strategy (sequence of the learning resources) of the learners need to be designed according to the learner types, needs and context using pedagogical design principles.

- Media enhancements: Quality of the media elements (graphics, audio and animation) plays a major role in any e-learning content.

- Interactivity: During design of the content, interactivity features need to be taken into consideration, to increase the level of interaction of learners with the learning process.

- Testing and feedback: The tester has the following choices: to use complete or partial verification, unit or integration, and black box or white box testing depending on the nature of learning application and the profile of the student. The major testing techniques in this area are as follows: a) Functional Testing. This black box testing could be used for the testing the forms for the course registration, fee submission and other interaction with the students. The procedure for checking pop-up windows, searches, online payments are also defined under this testing technique. b) Usability testing. The feedback about structure, feature, navigation and other factors are taken in this technique. Separate task lists are required to study students profile and the impact of the application. Testing will fail if the application contains outdated information, non-standard colours, long scrolling page, orphan page, excessive use of marquee, etc. It involves student behavioural pattern while using the e-learning application.

- Collaboration: Interaction and cooperation among learners and instructors regardless of where they are. This can be made possible through email exchange, discussion groups and bulletin boards.

- Content Standard Compliance: In modern education, 
learning technology standards are critical to its success because the content can be mixed and matched from multiple sources. Content can also be reused, assembled and disassembled quickly and easily.

- Content aggregation: Individual content sequencing and aggregation preferences should also be taken into consideration during instructional design.

Learner services elements: The software module should manage the following factors.

- User authentication: In e-learning end users need to access different e-learning modules daily to gain the knowledge. E-learning platforms need to implement proper authentication system to handle the authentication and authorization processes.

- Portfolio information: Personal digital collection of information describing a person's learning, career, experience and achievements are needed to be collated and preserved.

- Records of users' activity: Evaluating an e-learning system, user's activity / interaction between an e-learning system and its users should be taken into consideration.

Program delivery elements: An e-learning course can be a complete failure if $\mathrm{HCI}$ (Human Computer Interaction) design is poor. During design phase of the content, following HCI considerations should be taken into account.

- Design of the graphic elements: Graphic design is the process and art of combining text and graphics and communicating an effective message in the design of logos, graphics, brochures, newsletters, posters, signs, and any other type of visual communication.

- Colour scheme: Colour is possibly the most visually commanding aspect of any graphical user interface. Appropriate use of colour can enhance communication and aesthetics of an application and contributes to learner satisfaction. Colour should integrate well with other elements in the visual design, such as icons and text.

- Type of fonts: Text is necessary to communicate most messages. A small number of typefaces which must be legible, clear, and distinctive (i.e., distinguish between different classes of information) should be used.

- Navigational scheme / elements: Navigation between screens should be easy. Function and utility of each button / icon of the navigational elements should be mentioned in a 'Help' screen.

- Graphical User Interface /Page layout: To provide the user with a clear and consistent conceptual structure, the designer should focus on some important concepts i.e., consistency, screen layout, relationships and navigability.

Technological infrastructure elements: Success of the online courses is very much dependent on the following technological elements.

- Network bandwidth: Sufficient internet bandwidth should be available for seamless access of e-learning content over Internet. Proper use of media file format and streaming concept specifically for audio, video and animation reduces the network bandwidth.

- End users' system configuration: Recommended system configuration for end users' need to be maintained for accessing e-learning courses.
- Server configuration: End users' request handling capacity of the server on which e-learning content is deployed should be tested properly.

- Browser software: Access of e-learning content should not be browser dependent. Relevant plugins requirement for different type media (audio, video, animation etc.) access should also be taken into consideration.

- Database connectivity: Efficient connection mechanism / technique should be used for the connection between database and e-learning web pages.

- Technology (frame work): Used for deploying the content: Different content providers contribute content in an e-learning environment. So proper framework (technology) should be used for deploying quality e-learning contents.

- Interoperability / cross platform: During content creation, selection of technology and framework should be such that interoperability is properly maintained.

These five aspects of e-learning quality form the foundation of a general framework of quality criteria upon which the contribution of an e-learning quality approach can be assessed.

\section{QUALITY ASPECTS OF THE UNIVERSITY CONSORTIUM}

In the proposed framework of University Consortium, both quality of education and quality of system functioning are taken into consideration. Using a questionnaire that we designed, the respondents (experts) were requested to give their preferences on these characteristics and sub-characteristics proposed in our technique.

To implement the improvements of quality of learning objects, and further improving quality of education, the framework has incorporated the following areas and their relevant elements.

- Instructional elements

- Instructional design elements

- Learner service elements

- Program delivery elements

- Technological infrastructure elements

Framework support for Instructional elements: The framework provides the required units and their interconnectivity so that subject content is updated and maintained purposefully. Whenever any content from member institution is published in the University Consortium - the UDDI registry, a mail is sent to a content expert for his/her opinion about the content (quality, authenticity, validity, media, presentation and copyright). Similarly, opinions from an instructional expert are sought to make suggested changes in the content. Contents are improved in terms of quality and, thereby, become ready to use or reach an approved state [9]. For these, it is assumed that whenever the system wants to develop and deliver a new learning resource (module), it aggregates all the required SCOs using SCORM Aggregation Model. The system first searches its own repository and then it searches the UDDI registry using standard metadata to collect the SCOs. The system also checks the UDDI registry for the approved SCOs for this module.

Framework support for design elements: Whenever any 
content from member institution is published in the University Consortium - the UDDI registry, a mail is sent to a content expert for his/her opinion about the instruction design of sequencing and profiles (concept identification, pedagogical styles, media enhancements, interactivity, testing and feedback, collaboration, content standard compliance and Content aggregation). Similarly, an instructional expert makes his/her suggestions which are incorporated thereafter. Contents are improved in terms of quality and, thereby, become ready to use or reach on approved state [9]. Clear and explicit teaching strategy (sequence of the learning objects) of the learners need to be designed according to the learner types, needs and context using pedagogical design principles. The framework suggests storage of these strategies in the pedagogical repository. During delivery of the content to the learners, teaching strategy suited for those learners would be taken into consideration by taking inputs from pedagogical repository. The framework supports would remain so that necessary paths for the experts to update pedagogical inputs regularly are provided in the proposed framework [2].

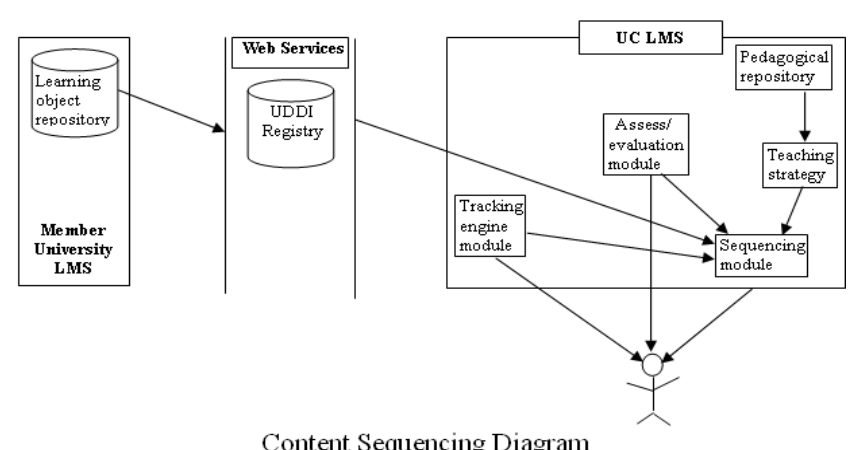

Framework support for Learner service elements: In the proposed framework, tracking engine module tracks the learners activity (last login time, time spent in last session, how much content is read during last session etc.) while the learner goes through the content. The "assess / evaluation manager" module measures the learners' performance [2]. According to the learners' performance appropriate feedbacks and suggestions are given. After creating a new session, taking inputs of these two modules, the appropriate content is served to the learners. In other words, dynamic sequencing of the SCOs is done based on the individual performance at run time.

Framework support for design principles Program delivery elements: The framework provides the required unit for checking the proper use of design principles of learning content. During design of the system framework, interactivity features are taken into consideration to increase the level of interaction of learners with the learning process. Whenever any content from member institution is published in the University Consortium - the UDDI registry, a mail is sent to an instructional expert for his/her opinion about the design element (design of the graphic elements, color scheme, type of fonts, navigational scheme / elements and graphical user interface / page layout). Similarly, the instructional expert can make his/her suggestions to make desired changes in the content and send out intimation for doing the same. Contents are improved in terms of quality and become ready to use or reach on approved state [9].

Framework support for technological infrastructure elements: Web Services technology remains a possible technology in academic business. This can be incorporated in the management of resources to support e-learning activities such as running courses, support students as well as background process seamlessly, between member institutions and University Consortium [2]. Web services are a distributed middleware technology that uses a simple XML based protocol to allow applications to send and receive data across the Web. Services are described in terms of the communication received and response sent. Information regarding digital learning resources can be retrieved by sending a SOAP query to the UDDI Registry which is like a remote database. To get the desired learning resource, a request is made based on the query retrieved from the UDDI Registry to the WSDL repository. This could be sent over a transport protocol like HTTP. Then finally, the WSDL document containing the description of the desired learning content is retrieved and forwarded to the LMS by sending an SOAP request over HTTP. The learner or the discoverer is able to discover the digital resources simply by sending a SOAP query over HTTP. In this way, quality factors network bandwidth, database connectivity, technology (framework) used for deploying content, and interoperability (cross platform) can be addressed. End users' system configuration, Server configuration and Browser software parameters can also be addressed.

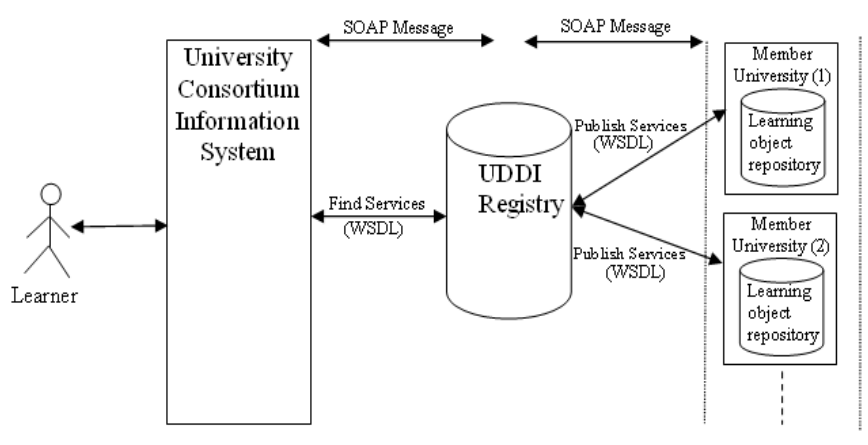

University Consortium Communic ation System

\section{CONCLUSION}

There is a need to assure the University Consortium members that learners are getting highly rated e-content that suits their requirements, and also necessary measures have been taken to improve other quality aspects of the system itself.

Feedback of the experts and system utility module can be taken in terms of a given numerical value, and with the help of statistical methods, a decision can be taken regarding the quality aspects of the e-learning system. In this way, the proposed framework can be extended further.

\section{REFERENCES}

[1] U. Rahul, Z. Wasefer, and B. P. Nath, "A Web Services Oriented Architecture for University Consortium," in Proceedings 2nd National Conference on Recent Trends in Information Systems (ReTIS-08), Jadavpur University, February 7-9, 2008. 
[2] Z. Wasefer and B. P. Nath, "A Framework of a University Consortium Information System," in Proceedings Best Practices in Engineering Education, Pune, India, $2^{\text {nd }}$ and $3^{\text {rd }}$ February, 2007.

[3] P. KOŠČ, G. M. TimčÁK, and P. BOBER, "Quality Initiatives in E-Learning, Acta Electrotechnica et Informatica," vol. 9, no. 1, 2009, 63-67.

[4] M. Abdellatief, A. B. Md Sultan, M. A. Jabar, and R. Abdullah, "A Technique for Quality Evaluation of E-Learning from Developers Perspective," American Journal of Economics and Business Administration vol. 3, no. 1, pp. 157-164, 2011

[5] C. M. Ionascu and B. Dorel, "A Model Of Analysis Of The E-Learning System Quality, Revista Tinerilor Economisti," The Young Economists Journal, vol. 1, issue 13, pp. 136-143, 2009

[6] E. Kurilovas, "Methods of Multiple Criteria Evaluation of the Quality of Learning Management Systems for Personalised Learners Needs,
Learning in the Synergy of Multiple Disciplines," in Proceedings of the EC-TEL 2009, volume 5794 von Lecture Notes in Computer Science, Berlin/Heidelberg, Springer, (Oktober 2009).

[7] R. Lanzilotti, C. Ardito, M. F. Costabile, and A. De Angeli, "eLSE Methodology: a Systematic Approach to the e-Learning Systems Evaluation," Educational Technology and Society, vol. 9, no. 4, pp. 42-53, 2006

[8] F. Deepwell, "Embedding Quality in e-Learning Implementation through Evaluation," Educational Technology and Society, vol. 10, no. 2, pp. 34-43, 2007

[9] W. Zaman and P. N. Basu, "A Framework to Incorporate Quality Aspects for E-Content in a Consortium Environment," in Proceedings Annual International Conference on Education and e-Learning EeL 2011, Hotel Fort Canning, Singapore, November 7 - 8, 2011. 